\title{
The Energy Saving for Separately Excited DC Motor Drive via Model Based Method
}

\author{
Sasiya Udomsuk*, Kongpol Areerak ${ }^{\dagger}$ and Kongpan Areerak*
}

\begin{abstract}
The model based method for energy saving of the separately excited DC motor drive system is proposed in the paper. The accurate power loss model is necessary for this method. Therefore, the adaptive tabu search algorithm is applied to identify the parameters in the power loss model. The field current values for minimum power losses at any load torques and speeds are calculated by the proposed method. The rule based controller is used to control the field current and speed of the motor. The experimental results confirm that the model based method can successfully provide the energy saving for separately excited DC motor drive. The maximum value of the energy saving is $48.61 \%$ compared with the conventional drive method.
\end{abstract}

Keywords: Adaptive tabu search, Energy saving, Model based method, Rule based controller, Separately excited DC motor

\section{Introduction}

Nowadays, the separately excited DC motor is widely used in industries. This motor is suitable for the electric vehicle and conveyer [1] because it can provide the high torque to drive the load. Moreover, this motor is easy to control the speed for automatic control system. Presently, the energy saving in electrical system is a considered issue for industrial sectors, particularly in the electric motor drive. Therefore, the energy saving of the separately excited DC motor is proposed in the paper. In the previous works [2-7], the conventional approach based on mathematics is applied to calculate the field current for energy saving. Unfortunately, the equation used in that approach is complicated and it is difficult to solve this problem. Therefore, the new method called the model based method (MBM) is used to calculate the field current for energy saving easily at any load torques and speed commands. The accurate power loss model is very important for the MBM method. Hence, the artificial intelligence technique called adaptive tabu search (ATS) is applied to identify the parameters in the power loss model. The ATS method is developed by Puangdownreong et al. in 2002 [8]. In order to perform its effectiveness, the ATS has been tested against several well-known benchmark functions, that is, Bohachevsky, Rastrigin, Shekel's foxholds, Shubert and Schwefel functions [9-13]. Moreover, the convergence property of the ATS has been proved to assure that it can reach the optimal solution within finite search time [9-14].

$\dagger \quad$ Corresponding Author: Power electronics, Energy, machines and Control Research Group, School of Electrical Engineering, Suranaree University of Technology, Thailand. (kongpol@sut.ac.th)

* Power electronics, Energy, machines and Control Research Group, School of Electrical Engineering, Suranaree University of Technology, Thailand.

Received: August 6, 2014; Accepted: September 9, 2015
Thus, the ATS algorithm can provide the global solutions for system identification. A single - phase bridge rectifier connected with two buck converters is a studied system in the paper as shown in Fig. 1. The expert controller called the rule based controller [15] is also presented for the field and speed controls. This controller is easy to implement and sufficient to control the field current and speed of the motor. In addition, the results of the electric energy consuming of the motor using the conventional drive method are compared with the MBM drive method. The results from the implementation in laboratory can confirm that the MBM method can provide the minimum losses at any load torques and speed commands. The maximum percent of the energy saving using the MBM drive method is equal to $48.61 \%$ compared with the conventional drive method. However, the MBM method cannot provide to save the energy in case of the high load torque.

The reviews of power losses of the separately excited DC motor and the identification of the power loss model

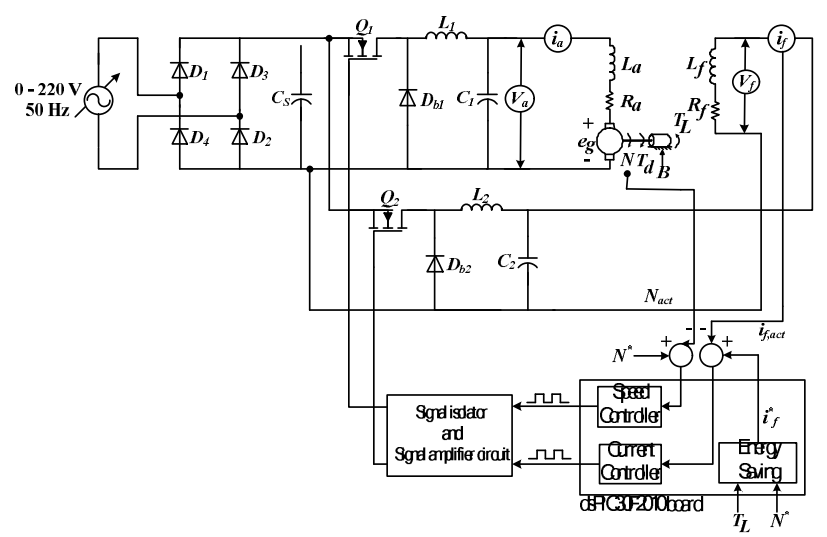

Fig. 1. The block diagram of a separately excited DC motor drive for energy saving 
are presented in Section 2. The energy saving algorithm using the MBM method and the design of rule based controllers are fully described in Section 3 and 4, respectively. The experimental results of the energy saving using the MBM drive method compared with the conventional drive method and discussion are shown in Section 5. Finally, Section 6 concludes the overall advantages using the MBM method to save the energy in separately excited DC motor drive system.

\section{Power Losses of Separately Excited DC Motor and Power Losses Identification}

\subsection{Power losses of separately excited DC motor}

The power losses can be classified into five types. These losses are both electrical and mechanical losses. The details of the losses are described in this section.

\subsubsection{Copper losses}

The copper losses are divided in two cases. These losses consist of the armature and field copper losses that can be calculated by (1).

$$
\begin{aligned}
& P_{a}=i_{a}^{2} R_{a} \\
& P_{f}=i_{f}^{2} R_{f}
\end{aligned}
$$

\subsubsection{Friction and windage losses}

These losses occur from the friction of the bearings in the motor and the friction between the moving parts of the motor and the air in the motor case [16]. These losses are given in (2).

$$
P_{m}=K_{m} N^{3}
$$

\subsubsection{Core loss}

The core loss occurs in the iron core of the motor. The core loss consists of the hysteresis loss $[2,16]$ and the eddy current loss [17] defined by (3).

$$
P_{i}=K_{h} \omega i_{f}^{2}+K_{e} \omega^{2} i_{f}^{2}
$$

\subsubsection{Brush loss}

This loss that occur the voltage drop across the brushes in the motor can be calculated by (4).

$$
P_{B D}=U_{e} i_{a}
$$

\subsubsection{Stray loss}

The stray loss depended on the armature current and the motor speed can be calculated by (5).

$$
P_{s}=K_{s t} i_{a}^{2} N^{2}
$$

The friction and windage losses and eddy current loss are neglected because the motor using in the paper is small horsepower $(0.5-\mathrm{hp})$. Therefore, the total power losses can be defined by (6).

$$
\begin{aligned}
P_{\text {loss }}=i_{a}^{2} R_{a}+ & i_{f}^{2} R_{f}+2 i_{a} \\
& +3600 K_{s t} i_{a}^{2} \omega^{2} / 4 \pi^{2}+K_{h} i_{f}^{2} \omega
\end{aligned}
$$

\subsection{Power Losses Identification}

In the paper, the total power losses can be calculated by (6). The accurate parameters in (6) are necessary to achieve the precise total power losses value. Thus, the method to identify the power loss parameters is presented in this section. The armature current $\left(i_{a}\right)$, field current $\left(i_{f}\right)$, and motor speed ( $\omega$ ) values in (6) can be measured by sensors, while armature resistance $\left(R_{a}\right)$ and field resistance $\left(R_{f}\right)$ are also measured by an ohmmeter. In the paper, $R_{a}$ and $R_{f}$ are equal to $16 \Omega$ and $735 \Omega$, respectively. Moreover, the coefficients of the stray losses $\left(K_{s t}\right)$ and hysteresis losses $\left(K_{h}\right)$ in $(6)$ are difficult to measure or calculate. In previous researches [3], the equation to calculate the $K_{s t}$ and $K_{h}$ values are not appeared. Therefore, the identification of two parameters are necessary. In the paper, the artificial intelligence technique called adaptive tabu search method (ATS) is applied to identify these parameters $\left(K_{s t}\right.$ and $\left.K_{h}\right)$. The ATS method is confirmed by [8] to achieve the global solution. The back tracking and adaptive search radius are the main mechanisms of the ATS method to escape the local solution to global solution. The block diagram to identify the power loss parameters in the paper is illustrated in Fig. 2.

In Fig. 2, the equation (7) is used as the objective function to calculate the cost value $(W)$. This equation is the root mean square error between the power loss values from experiment $\left(P_{\text {loss(experiment })}\right)$ and computation

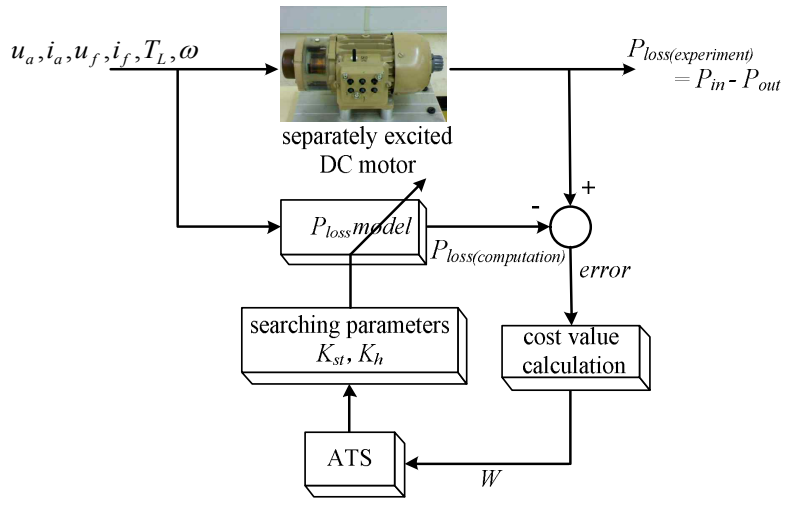

Fig. 2. The block diagram to identify the parameters of power loss equation using ATS algorithm 
Table 1. The motor testing results

\begin{tabular}{c|c|c|c|c|c|c|c|c|c}
\hline \multicolumn{2}{c|}{ speed } & \multirow{2}{*}{$u_{a}(\mathrm{~V})$} & \multirow{2}{*}{$i_{a}(\mathrm{~A})$} & \multirow{2}{*}{$u_{f}(\mathrm{~V})$} & \multirow{2}{*}{$i_{f}(\mathrm{~A})$} & $T_{L}(\mathrm{~N} \cdot \mathrm{m})$ & \multirow{2}{*}{$P_{\text {in }}(\mathrm{W})$} & \multirow{2}{*}{$P_{\text {out }}(\mathrm{W})$} & \multirow{2}{*}{$P_{\text {loss }}(\mathrm{W})$} \\
\hline \% rated speed & $\mathrm{rad} / \mathrm{s}$ & & 2.20 & 220.00 & 0.30 & 1.54 & 468.16 & 304.28 & 163.88 \\
\hline 80 & 197.71 & 182.80 & 2.20 & 1.54 & 508.64 & 342.53 & 166.11 \\
\hline 90 & 22.43 & 201.20 & 2.20 & 220.00 & 0.30 & 1.30 \\
\hline 100 & 247.87 & 220.00 & 2.20 & 220.00 & 0.30 & 1.55 & 550.00 & 383.71 & 166.29 \\
\hline 110 & 270.28 & 220.00 & 2.20 & 186.50 & 0.22 & 1.39 & 524.10 & 374.34 & 149.76 \\
\hline 120 & 297.40 & 220.00 & 2.20 & 143.30 & 0.19 & 1.23 & 511.23 & 365.81 & 145.42 \\
\hline
\end{tabular}

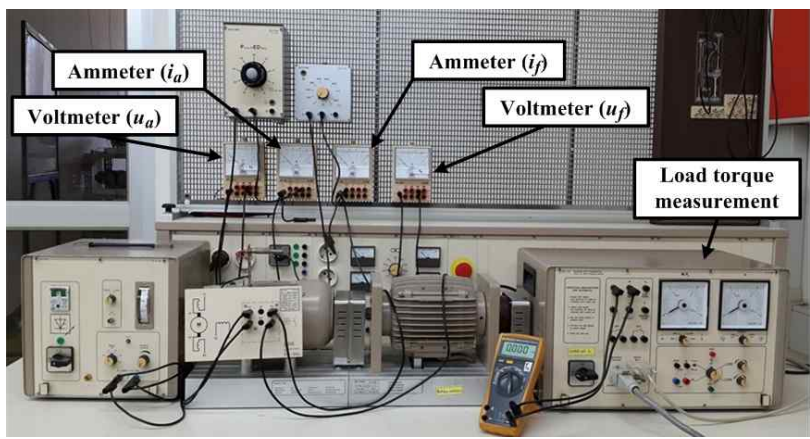

Fig. 3. The experimental rig for testing

$\left(P_{\text {loss(computation) }}\right)$ as given in (8). The $n$ value in (7) is the total data number. The experimental rig to measure the $\left(P_{\text {loss(experiment })}\right)$ is depicted in Fig. 3. In addition, the results from motor testing at $80 \%, 90 \%, 100 \%, 110 \%$ and $120 \%$ of rated speed are shown in Table 1 . The data of $80 \%, 100 \%$ and $120 \%$ of rated speed are used to identify the power loss parameters $\left(K_{s t}\right.$ and $\left.K_{h}\right)$, while the data of $90 \%$ and $110 \%$ of rated speed are used for validation.

$$
\begin{gathered}
W=\sqrt{\frac{\sum \text { error }^{2}}{n}} \\
\text { error }=\left|P_{\text {loss(experiment) }}-P_{\text {loss(computation) }}\right|
\end{gathered}
$$

From Fig. 2, the ATS is applied to search the $K_{s t}$ and $K_{h}$ parameters. The new $K_{s t}$ and $K_{h}$ values from ATS searching is used to calculate the power losses $\left(P_{\text {loss(computation) }}\right)$. The new $P_{\text {loss(computation) }}$ value calculated by using the new $K_{s t}$ and $K_{h}$ parameters is subtracted with $P_{\text {loss(experiment) }}$ again. The ATS process is used to tune the $K_{s t}$ and $K_{h}$ values until the minimum $W$ value can be obtained. The convergence of $W$ value is shown in Fig. 4. In this paper, the initial solutions for ATS searching are determined by random. However, the authors define the suitable search space that can provide the initial solution as better as possible. As a result, the $W$ value is equal to 4 at the beginning. If the search space is not appropriate, the initial $W$ value will be higher than 4 . As for this case, the count for ATS searching equal to 20 is not enough to achieve the best solution. The more details of the ATS searching process can be found in [8]. The results from the power loss parameters identification with ATS algorithm are shown in Table 2. In Table 2 , the $K_{h}$ value from the $1^{\text {st }}$ experimental is different from the others because of the

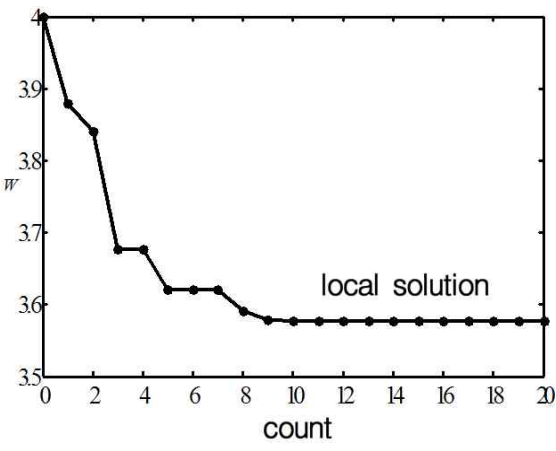

Fig. 4. The $W$ convergence

Table 2. The ATS searching results and the validation results of the power loss equation

\begin{tabular}{c|c|c|c}
\hline \multicolumn{5}{c}{ The ATS searching results } \\
\hline Testing & $K_{\text {st }}\left(\mathrm{W} \cdot \mathrm{s}^{2} / \mathrm{A}^{2}\right)$ & $K_{h}\left(\mathrm{~W} \cdot \mathrm{s} / \mathrm{A}^{2} \cdot \mathrm{rad}\right)$ & $W$ \\
\hline $1^{\text {st }}$ & $8.68 \times 10^{-7}$ & $2.89 \times 10^{-8}$ & 3.5764 \\
$2^{\text {nd }}$ & $8.68 \times 10^{-7}$ & $5.10 \times 10^{-8}$ & 3.5764 \\
$3^{\text {rd }}$ & $8.68 \times 10^{-7}$ & $5.34 \times 10^{-8}$ & 3.5764 \\
$4^{\text {th }}$ & $8.68 \times 10^{-7}$ & $4.28 \times 10^{-8}$ & 3.5764 \\
$5^{\text {th }}$ & $8.68 \times 10^{-7}$ & $6.23 \times 10^{-8}$ & 3.5764 \\
Averaged value & $\mathbf{8 . 6 8 \times 1 0 ^ { - 7 }}$ & $\mathbf{4 . 7 7} \times \mathbf{1 0}^{-8}$ & $\mathbf{3 . 5 7 6 4}$ \\
\hline \multicolumn{4}{c}{ The validation results of the power loss equation } \\
\hline \% of rated speed & $P_{\text {loss(experiment })}(\mathrm{W})$ & $P_{\text {loss(computation })}(\mathrm{W})$ & \% error \\
\hline 90 & 166.11 & 166.93 & 0.49 \\
\hline 110 & 149.76 & 143.77 & 4 \\
\hline \multicolumn{4}{c}{}
\end{tabular}

random process of the initial solution in ATS searching. In the paper, the ATS searching process was conducted 5 trials with random initial solutions. Therefore, the average values of $K_{h}$ and $K_{s t}$ are suitable for using in the paper. The average values of $K_{s t}$ and $K_{h}$ are equal to $8.68 \times 10^{-7}$ $\mathrm{W} \cdot \mathrm{s}^{2} / \mathrm{A}^{2}$ and $4.77 \times 10^{-8} \mathrm{~W} \cdot \mathrm{s} / \mathrm{A}^{2} \cdot \mathrm{rad}$, respectively. It can be seen from the results that the $K_{s t}$ and $K_{h}$ values are very small because the motor using in the paper is a small size. In addition, the parameters validation is necessary to guarantee the identification results. The validation results show that the $K_{s t}$ and $K_{h}$ values are appropriate to use at any operating points. Therefore, the equation to calculate the total power losses of the motor using in the paper is shown in (9). In the paper, the voltage drop across the brushes $\left(U_{e}\right)$ is set to $2 \mathrm{~V}[1]$.

$$
\begin{aligned}
P_{\text {loss }}= & 16 i_{a}^{2}+735 i_{f}^{2}+2 i_{a} \\
& +\left(7.92 \times 10^{-5}\right) i_{a}^{2} \omega^{2}+\left(4.77 \times 10^{-8}\right) i_{f}^{2} \omega
\end{aligned}
$$




\section{Energy Saving using Model Based Method}

\subsection{The conventional method}

The conventional method to control the speed of the separately excited DC motor is divided into two cases. In the first case, the armature voltage control can be adjusted, while the field voltage is set to be constant at rated value. For this case, the speed command is less than the rated speed. In the second case, the speed command is more than the rated speed. The armature voltage is fixed to rated and the field voltage is adjusted to increase the motor speed. The input power $\left(P_{i n}\right)$ calculation of the motor for conventional control approach can be calculated by (10).

$$
P_{i n}=u_{a} i_{a}+u_{f} i_{f}
$$

\subsection{The model based method}

In the paper, the new method to minimize the power losses for separately excited DC motor is presented. This method is called the model based method (MBM). The
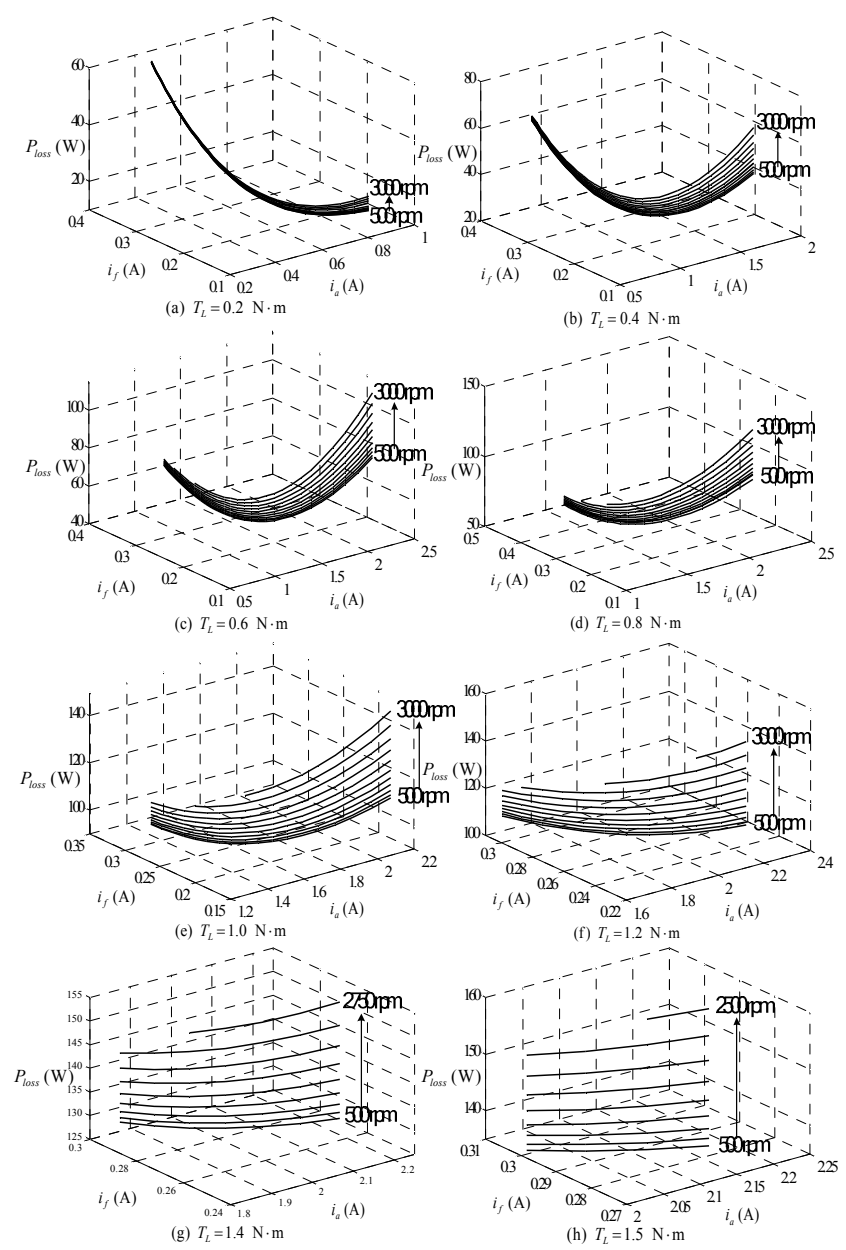

Fig. 5. The minimum power loss at any speeds and load torques
MBM is applied to calculate the field current for energy saving at any operating points. The total power loss values calculated by (9) from section 2.2 at load torque $\left(T_{L}\right)$ equal to $0.2,0.4,0.6,0.8,1.0,1.2,1.4$ and $1.5 \mathrm{~N} \cdot \mathrm{m}$ are shown in Fig. 5. From this figure, the motor speed and field current are varied from 500-3000 rpm and 0.1-0.3 A, respectively. The armature currents in Fig. 5 are calculated by the basic equation as shown in (11) using $K=2.49 \mathrm{~N} \cdot \mathrm{m} / \mathrm{A}^{2}$.

$$
\begin{gathered}
i_{a}=T_{L} / K i_{f} \\
i_{f}=a_{0}+a_{1} N
\end{gathered}
$$

From Fig. 5, it can be seen that the minimum power loss value is depended on the field current at any load torques and speeds. Therefore, the field current for the minimum loss can be calculated. The optimal field current values for loss minimization at any load torques and speeds from Fig. 5 are shown in Fig. 6. The curve in Fig. 6 is called $i_{f}-N$ curve for loss minimization. In case of $T_{L}=$ $0.6 \mathrm{~N} \cdot \mathrm{m}$ and speed command $N=1500 \mathrm{rpm}$, the field current $\left(i_{f}\right)$ for minimum power loss is equal to $0.197 \mathrm{~A}$. The $i_{f}-N$ curve in Fig. 6 can be approximated by linear regression as depicted in Fig. 7. The equation (12) is used to approximate the $i_{f}$ value for loss minimization. The $a_{0}$ and $a_{1}$ coefficients at any load torques are shown

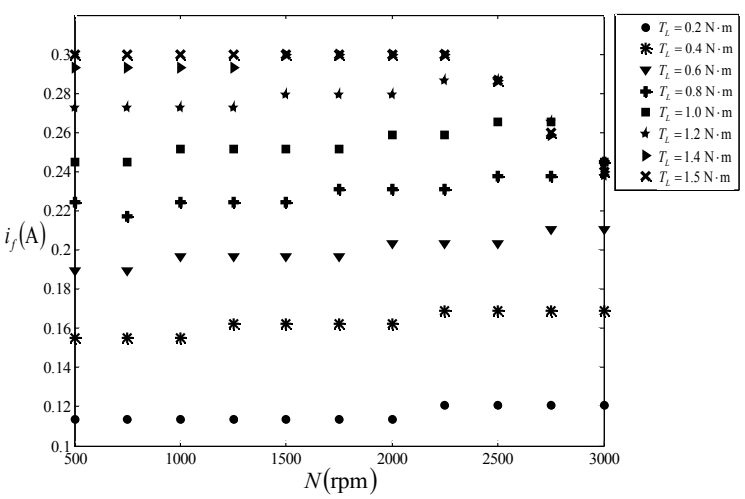

Fig. 6. The $i_{f}-N$ curves for loss minimization.

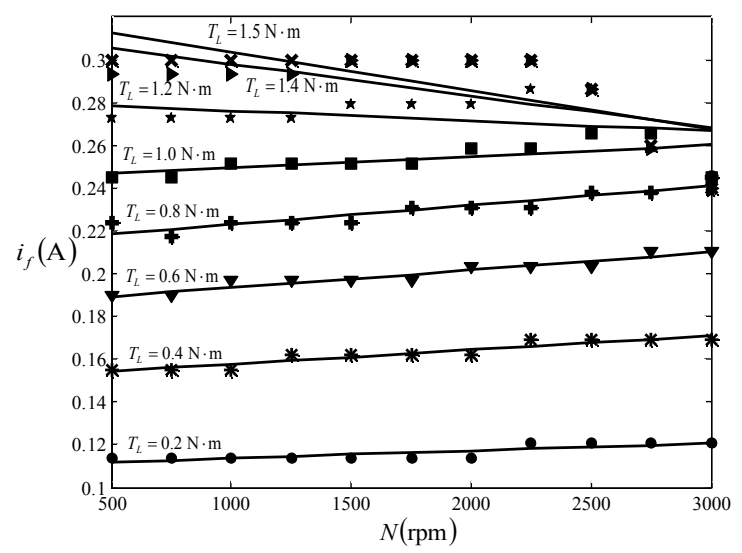

Fig. 7. The linear approximation of $i_{f}-N$ curve using linear regression method. 
in Table 3.

In Fig. 7, there are eight $i_{f}-N$ curves for $T_{L}=0.2,0.4$, $0.6,0.8,1.0,1.2,1.4$ and $1.5 \mathrm{~N} \cdot \mathrm{m}$. The $i_{f}-N$ curves for other load torques can be determined by using the linear interpolation method. The $a_{0}$ and $a_{1}$ coefficients from linear interpolation method can be calculated by the equations in Table 4. For example, if $T_{L}=0.3 \mathrm{~N} \cdot \mathrm{m}$, the equations to calculate the $a_{0}$ and $a_{1}$ coefficients can use the equations in $0.2<T_{L}<0.4$ interval. The $i_{f}-N$ curves for any load torques using the linear interpolate are shown in Fig. 8. In the paper, the equation (12) with the coefficients in Table 4 is used to calculate the field current for loss minimization at any load torques and speeds.

Table 3. The $a_{0}$ and $a_{l}$ coefficients from linear regression method

\begin{tabular}{c|c|c}
\hline$T_{L}(\mathrm{~N} \cdot \mathrm{m})$ & $a_{0}$ & $a_{I}$ \\
\hline 0.2 & 0.1112 & $3.5140 \times 10^{-6}$ \\
\hline 0.4 & 0.1513 & $6.5210 \times 10^{-6}$ \\
\hline 0.6 & 0.1852 & $8.2760 \times 10^{-6}$ \\
\hline 0.8 & 0.2140 & $9.0280 \times 10^{-6}$ \\
\hline 1.0 & 0.2444 & $5.2664 \times 10^{-6}$ \\
\hline 1.2 & 0.2810 & $4.7651 \times 10^{-6}$ \\
\hline 1.4 & 0.3130 & $1.4920 \times 10^{-5}$ \\
\hline 1.5 & 0.3220 & $1.8230 \times 10^{-5}$ \\
\hline
\end{tabular}

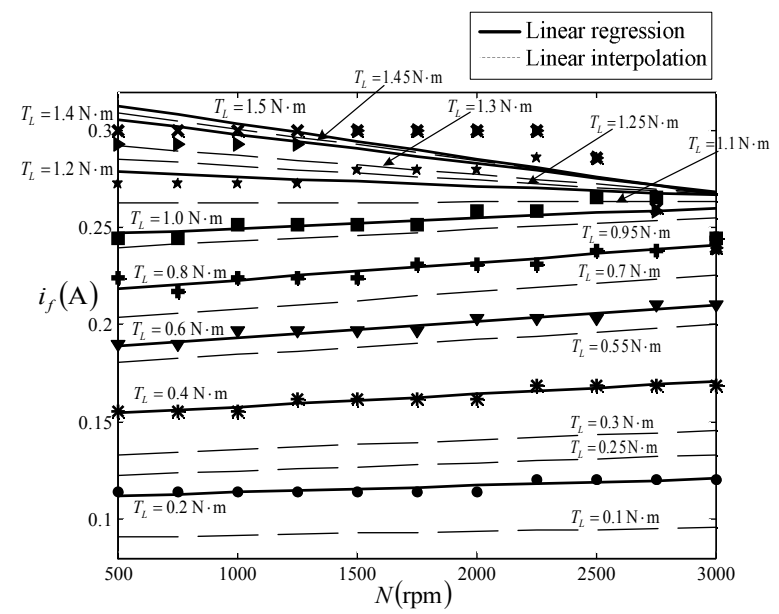

Fig. 8. The $i_{f}-N$ curves using linear interpolation method.

\section{Rule Based Controller}

The expert controller called the rule based controller is applied for speed and field current controls in the paper. The inference engine and knowledge based are the important parts of this controller. The rules of the controller are generated from the engineer experiences.

Table 4. The $a_{0}$ and $a_{1}$ coefficients from linear interpolation method

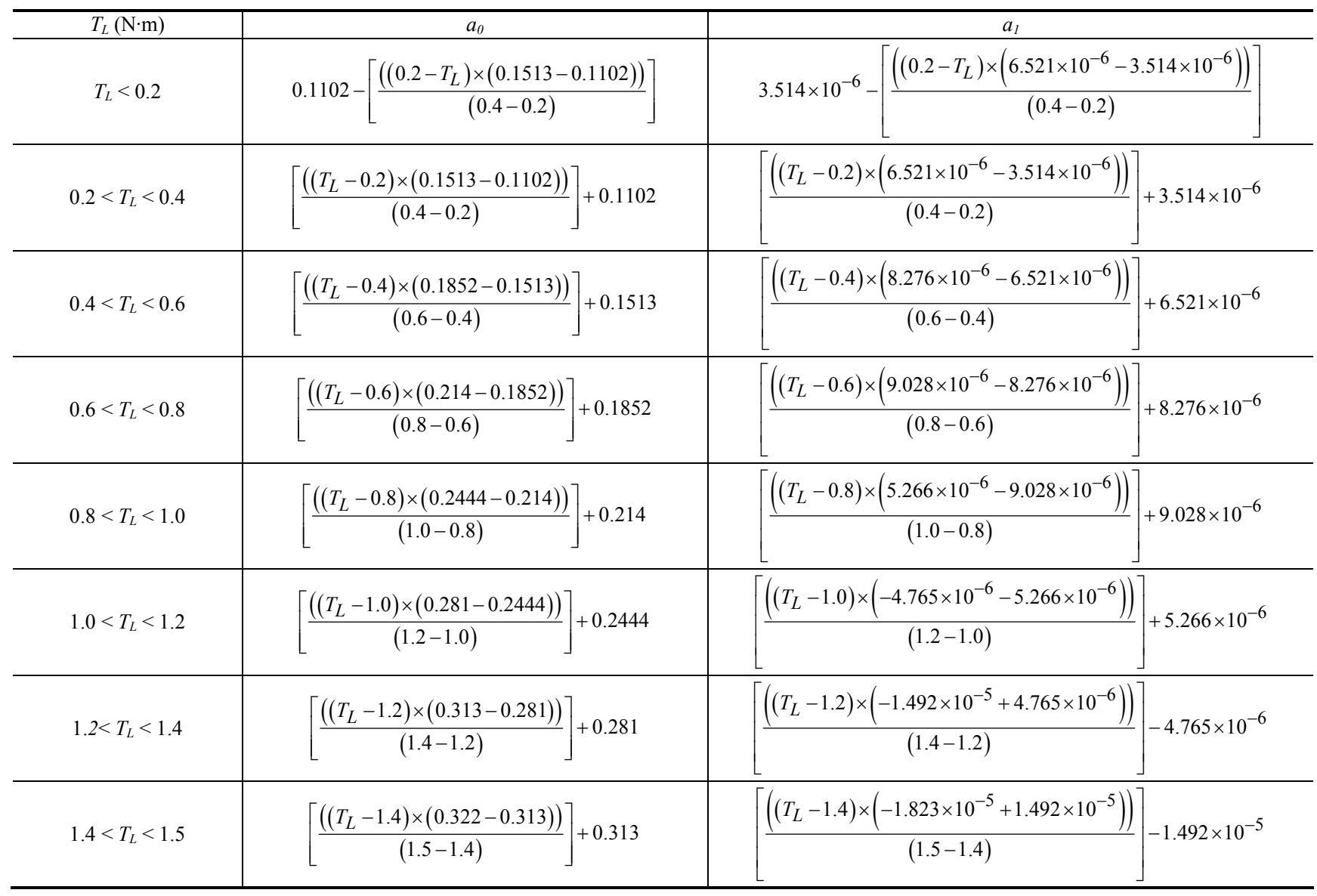




\subsection{Field current control}

The MBM method described in Section 3 is used to calculate the field current for loss minimization. The buck converter in the field side of Fig. 1 is used to adjust the field current to the command value. The duty cycle of $Q_{2}$ is adjusted by the rule based controller. There are ten rules for field current control.

\section{Rule 1:}

if $<e r r_{-} f$ is positive and more than $15 \mathrm{~mA}>$ then $<$ increase duty cycle $2.5 \%>$

Rule 2:

if $<e r r f$ is positive and more than $12 \mathrm{~mA}>$ then $<$ increase duty cycle $1.5 \%>$

Rule 3:

if $<e r r \quad f$ is positive and more than $10 \mathrm{~mA}>$ then $<$ increase duty cycle $1.0 \%>$

Rule 4:

if $<e r r \_f$ is positive and more than $7 \mathrm{~mA}>$ then $<$ increase duty cycle $0.5 \%>$

Rule 5:

if $<e r r f$ is positive and more than $5 \mathrm{~mA}>$ then $<$ increase duty cycle $0.1 \%>$

Rule 6:

if $<e r r_{-} f$ is negative and more than $15 \mathrm{~mA}>$ then $<$ decrease duty cycle $2.5 \%>$

Rule 7:

if $<e r r_{-} f$ is negative and more than $12 \mathrm{~mA}>$ then $<$ decrease duty cycle $1.5 \%>$

Rule 8:

if $<e r r_{-} f$ is negative and more than $10 \mathrm{~mA}>$ then $<$ decrease duty cycle $1.0 \%>$

Rule 9:

if $<e r r \quad f$ is negative and more than $7 \mathrm{~mA}>$ then $<$ decrease duty cycle $0.5 \%>$

Rule 10:

if $<e r r_{\_} f$ is negative and more than $5 \mathrm{~mA}>$

then $<$ decrease duty cycle $0.1 \%>$

The err $f$ in the rules is the error between the field current value for loss minimization calculated by MBM method $\left(i_{f, \text { minimize }}\right)$ and the actual field current $\left(i_{f, a c t}\right)$ as defined by (13). For example in Rule 1 , the $i_{f \text {,minimize }}$ is more than the $i_{f, a c t}$ (more than $15 \mathrm{~mA}$ ), the $e r r_{-} f$ is the positive value. In this case, the $i_{f, a c t}$ should be increased by increasing the duty cycle of $Q_{2} 2.5 \%$.

$$
e r r_{\_} f=i_{f, \text { minimize }}-i_{f, \text { act }}
$$

\subsection{Motor speed control}

The rule based controller is also used to control the motor speed to the desired value. The buck converter connected in the armature side in Fig. 1 is applied to adjust the armature voltage to control the motor speed. The duty cycle of $Q_{1}$ is adjusted by the eight rules of the rule based controller.

\section{Rule 1:}

if $<e r r_{-} s$ is positive and more than $200 \mathrm{rpm}>$ then $<$ increase duty cycle $1.5 \%>$

Rule 2:

if $<e r r_{-} s$ is positive and more than $100 \mathrm{rpm}>$ then $<$ increase duty cycle $1.0 \%>$

Rule 3:

if $<$ err $s$ is positive and more than $50 \mathrm{rpm}>$ then $<$ increase duty cycle $0.5 \%>$

Rule 4: if $<e r r_{-} s$ is positive and more than $10 \mathrm{rpm}>$ then $<$ increase duty cycle $0.1 \%>$

Rule 5:

if $<e r r_{-} s$ is negative and more than $200 \mathrm{rpm}>$ then $<$ decrease duty cycle $1.5 \%>$

Rule 6:

if $<e r r_{-} s$ is negative and more than $100 \mathrm{rpm}>$

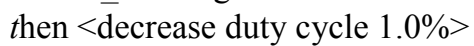

Rule 7:

if $<e r r_{-} s$ is negative and more than $50 \mathrm{rpm}>$ then $<$ decrease duty cycle $0.5 \%>$

Rule 8:

if $<e r r_{-} s$ is negative and more than $10 \mathrm{rpm}>$ then $<$ decrease duty cycle $0.1 \%>$

The $e r r_{-} s$ is the error between the speed command $\left(N^{*}\right)$ and the actual speed $\left(N_{a c t}\right)$ as shown in (14). For example in Rule 5 case, the $N_{a c t}$ is more than the $N^{*}$ (more than 200 $\mathrm{rpm})$, the $e r r_{-} s$ is the negative value. In this case, the duty cycle of $Q_{1}$ is decreased $1.5 \%$ to reduce the armature voltage.

$$
e r r_{-} s=N^{*}-N_{a c t}
$$

In the paper, the dsPIC30F2010 microcontroller is used to implement the rule based controllers for current and speed control loops. Moreover, the dsPIC30F2010 is used to calculate the $i_{\text {f,minimize }}$ using the MBM method for energy saving. The overall procedures for energy saving and controls are explained in Fig. 9. From this figure, the speed command $\left(N^{*}\right)$ and load torque $\left(T_{L}\right)$ are set by user $(\leq$ rated of the motor). After setting $N^{*}$ and $T_{L}$ values, the dsPIC30F2010 calculates the $i_{f \text {,minimize }}$ for energy saving using MBM method. The actual field current $\left(i_{f, a c t}\right)$ from current sensor is used to calculate the err_f $f$. The err $f$ value is the input of the rule based controller to adjust the duty cycle of $Q_{2}$. After the duty cycle adjustment to adapt the field current to command value $\left(i_{f, \text { minimize }}\right)$, the speed control is action. The actual speed $\left(N_{a c t}\right)$ from speed sensor is detected to calculate the err $s$. This error is used to check in eight rules for rule based controller. The controller adjusts the duty cycle $Q_{1}$ to change the armature voltage 


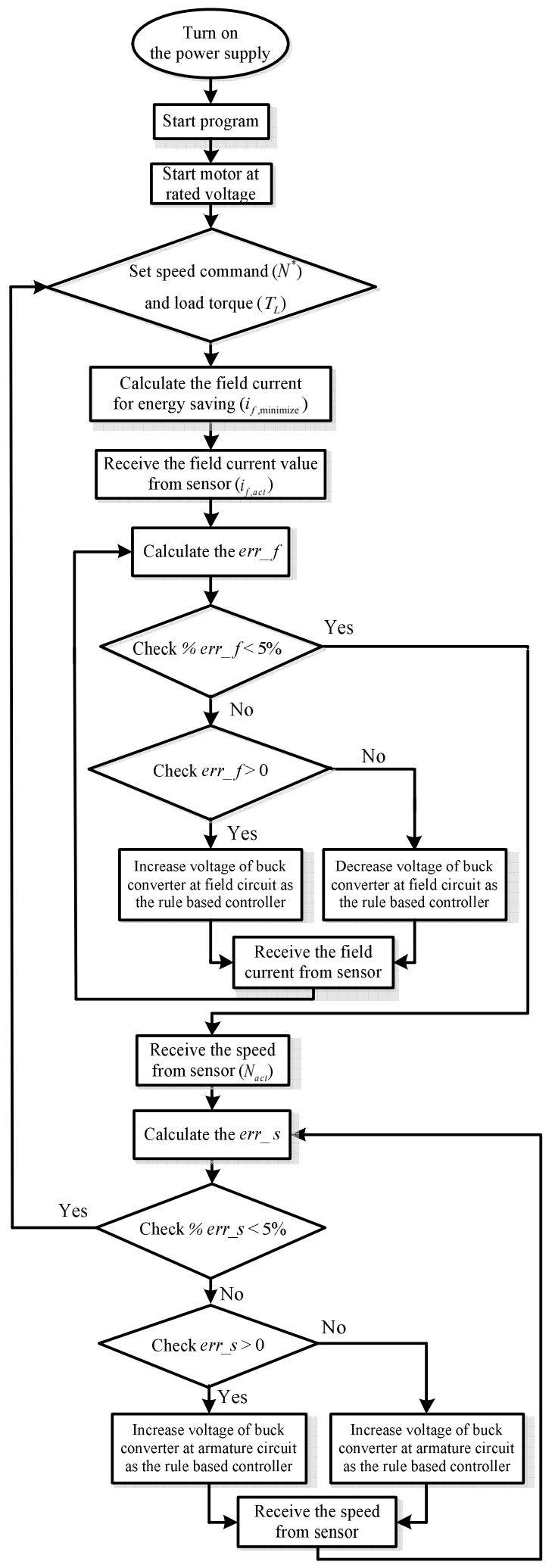

Fig. 9. The block diagram of motor drive with the rule based controller

for speed control. For this situation, the motor speed is equal to speed command and the field current is equal to $i_{f, \text { minimize }}$ for energy saving. In case of the speed command or variation of load torque, the dsPIC30F2010 calculates the new $i_{f, \text { minimize }}$ value again and the rule based controller starts to control the field current and motor speed to track the command value.

\section{Experimental Results and Discussion}

The experimental setup of the separately excited DC motor drive system is shown in Fig. 10. It can be seen in Fig. 10 that the single phase bridge rectifier connected with two buck converters are the power converters of the system.

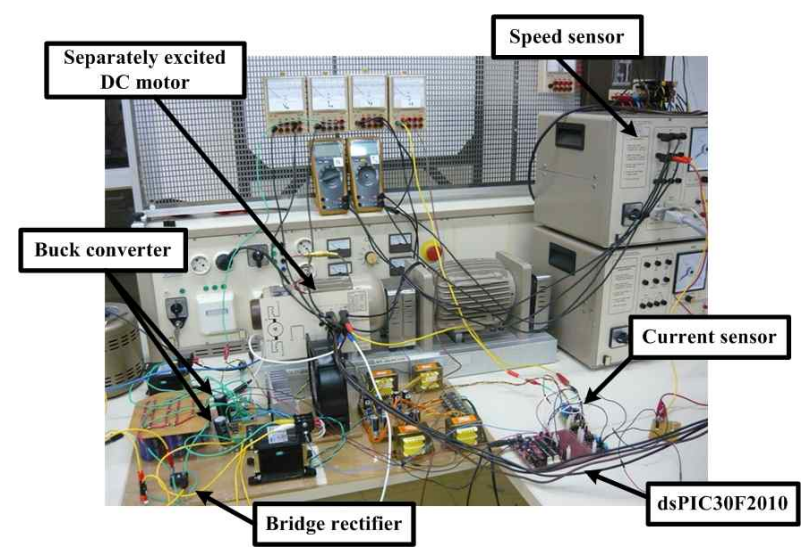

Fig. 10. A driving system for separately excited DC motor
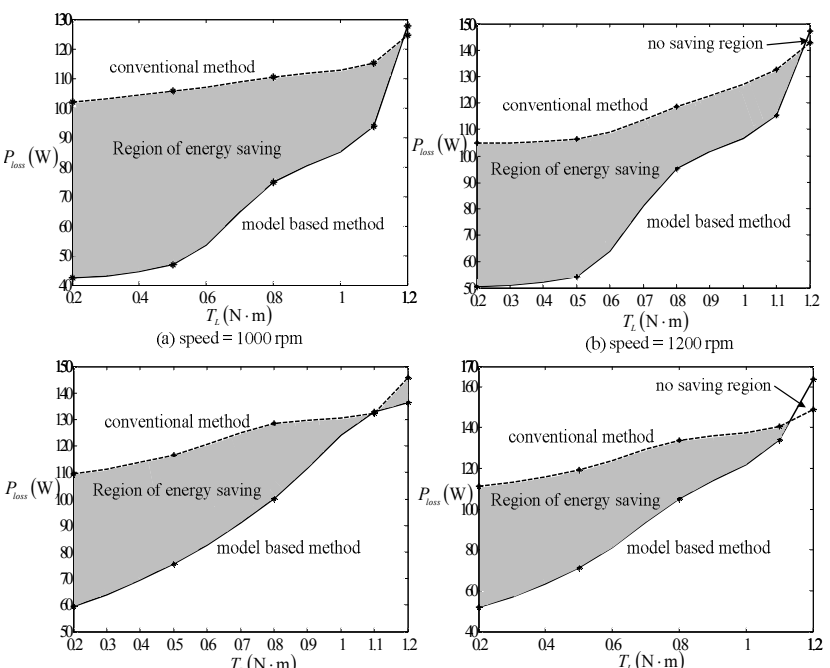

(b) speed $=1200 \mathrm{rpm}$
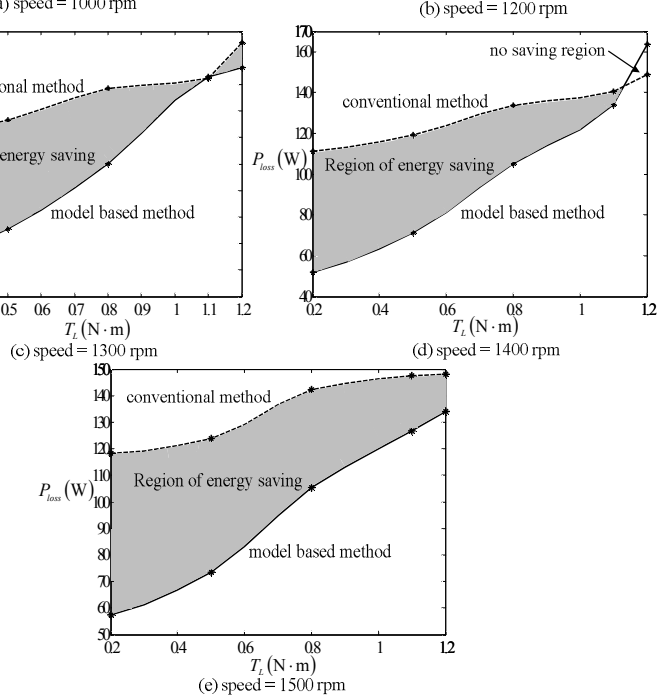

Fig. 11. The energy saving of the motor using difference technique to control the motor speed 
Table 5. The comparison results of energy saving

\begin{tabular}{|c|c|c|c|c|c|c|c|c|c|c|c|c|c|c|}
\hline \multirow{2}{*}{$\begin{array}{c}T_{L} \\
(\mathrm{~N} \cdot \mathrm{m})\end{array}$} & \multirow{2}{*}{$\begin{array}{c}N^{*} \\
(\mathrm{rpm})\end{array}$} & \multicolumn{6}{|c|}{ Conventional method } & \multicolumn{6}{|c|}{ Model based method } & \multirow{2}{*}{$\begin{array}{c}\% \text { loss } \\
\text { minimization }\end{array}$} \\
\hline & & $\begin{array}{c}N_{a c t} \\
(\mathrm{rpm})\end{array}$ & $\begin{array}{c}i_{f} \\
(\mathrm{~A})\end{array}$ & $\begin{array}{c}u_{f} \\
(\mathrm{~V})\end{array}$ & $\begin{array}{c}i_{a} \\
(\mathrm{~A})\end{array}$ & $\begin{array}{c}u_{a} \\
(\mathrm{~V})\end{array}$ & $\begin{array}{c}P_{i n, C O N} \\
(\mathrm{~W})\end{array}$ & $\begin{array}{c}N_{a c t} \\
(\mathrm{rpm})\end{array}$ & $\begin{array}{c}i_{f} \\
(\mathrm{~A})\end{array}$ & $\begin{array}{c}u_{f} \\
(V)\end{array}$ & $\begin{array}{c}i_{a} \\
(\mathrm{~A})\end{array}$ & $\begin{array}{c}u_{a} \\
\text { (V) }\end{array}$ & $\begin{array}{c}P_{i n, M B M} \\
(\mathrm{~W})\end{array}$ & \\
\hline \multirow{5}{*}{0.2} & 1000 & 1043 & 0.30 & 200 & 0.75 & 85 & 123.75 & 1012 & 0.12 & 80 & 0.90 & 60 & 63.60 & 48.61 \\
\hline & 1200 & 1205 & 0.30 & 200 & 0.70 & 100 & 130.00 & 1219 & 0.12 & 80 & 0.95 & 70 & 76.10 & 41.46 \\
\hline & 1300 & 1318 & 0.30 & 200 & 0.70 & 111 & 137.00 & 1341 & 0.11 & 70 & 1.00 & 80 & 87.70 & 35.99 \\
\hline & 1400 & 1395 & 0.30 & 200 & 0.70 & 115 & 140.50 & 1408 & 0.12 & 80 & 0.90 & 80 & 81.60 & 41.92 \\
\hline & 1500 & 1565 & 0.30 & 200 & 0.70 & 130 & 151.00 & 1495 & 0.11 & 70 & 0.90 & 90 & 88.70 & 41.26 \\
\hline \multirow{5}{*}{0.5} & 1000 & 1020 & 0.30 & 200 & 1.10 & 90 & 159.00 & 988 & 0.18 & 120 & 1.10 & 70 & 98.60 & 37.99 \\
\hline & 1200 & 1218 & 0.30 & 200 & 1.10 & 100 & 170.00 & 1211 & 0.18 & 120 & 1.20 & 80 & 117.60 & 30.82 \\
\hline & 1300 & 1335 & 0.30 & 200 & 1.10 & 115 & 186.50 & 1321 & 0.19 & 130 & 1.20 & 100 & 144.70 & 22.41 \\
\hline & 1400 & 1389 & 0.30 & 200 & 1.10 & 120 & 192.00 & 1401 & 0.17 & 115 & 1.25 & 100 & 144.55 & 24.71 \\
\hline & 1500 & 1513 & 0.30 & 200 & 1.10 & 130 & 203.00 & 1527 & 0.18 & 120 & 1.20 & 110 & 153.60 & 24.33 \\
\hline \multirow{5}{*}{0.8} & 1000 & 1010 & 0.30 & 200 & 1.50 & 90 & 195.00 & 1002 & 0.22 & 140 & 1.60 & 80 & 158.80 & 18.56 \\
\hline & 1200 & 1181 & 0.30 & 200 & 1.50 & 105 & 217.50 & 1184 & 0.23 & 150 & 1.60 & 100 & 194.50 & 10.57 \\
\hline & 1300 & 1332 & 0.30 & 200 & 1.50 & 120 & 240.00 & 1317 & 0.23 & 150 & 1.60 & 110 & 210.50 & 12.29 \\
\hline & 1400 & 1447 & 0.30 & 200 & 1.50 & 130 & 255.00 & 1447 & 0.23 & 150 & 1.60 & 120 & 226.50 & 11.18 \\
\hline & 1500 & 1502 & 0.30 & 200 & 1.60 & 130 & 268.00 & 1510 & 0.22 & 145 & 1.60 & 125 & 231.90 & 13.47 \\
\hline \multirow{5}{*}{1.1} & 1000 & 1006 & 0.30 & 200 & 1.90 & 90 & 231.00 & 1001 & 0.25 & 170 & 1.85 & 90 & 209.00 & 9.52 \\
\hline & 1200 & 1183 & 0.30 & 200 & 1.90 & 110 & 269.00 & 1169 & 0.27 & 185 & 2.00 & 100 & 249.95 & 7.08 \\
\hline & 1300 & 1268 & 0.30 & 200 & 1.90 & 115 & 278.50 & 1337 & 0.26 & 180 & 2.00 & 120 & 286.80 & oo saving \\
\hline & 1400 & 1446 & 0.30 & 200 & 1.90 & 130 & 307.00 & 1342 & 0.27 & 180 & 2.00 & 120 & 288.60 & 5.99 \\
\hline & 1500 & 1526 & 0.30 & 200 & 1.95 & 135 & 323.25 & 1460 & 0.25 & 180 & 2.00 & 125 & 295.00 & 8.74 \\
\hline \multirow{5}{*}{1.2} & 1000 & 990 & 0.30 & 200 & 2.10 & 90 & 249.00 & 995 & 0.28 & 180 & 2.25 & 90 & 252.90 & no saving \\
\hline & 1200 & 1180 & 0.30 & 200 & 2.10 & 110 & 291.00 & 1177 & 0.28 & 190 & 2.20 & 110 & 295.20 & no saving \\
\hline & 1300 & 1324 & 0.30 & 200 & 2.10 & 120 & 312.00 & 1238 & 0.27 & 185 & 2.20 & 110 & 291.95 & 6.43 \\
\hline & 1400 & 1380 & 0.30 & 200 & 2.10 & 125 & 322.50 & 1360 & 0.27 & 180 & 2.20 & 130 & 334.60 & no saving \\
\hline & 1500 & 1471 & 0.30 & 200 & 2.10 & 130 & 333.00 & 1457 & 0.28 & 190 & 2.20 & 120 & 317.20 & 4.74 \\
\hline
\end{tabular}

The dsPIC30F2010 microcontroller board is used to calculate the command value of field current for energy saving based on MBM method. Moreover, it acts as the current and speed controllers using rule based control technique. The rating of the separately excited DC motor using in the paper is $0.5-\mathrm{hp}, 220 \mathrm{~V}, 2360$-rpm, $2.2 \mathrm{~A}$. The conventional method and MBM described in Section 3 are applied to drive the motor. The experimental results using MBM method compared with the conventional method are depicted in Table 5. The load torque $\left(T_{L}\right)$ values for testing are in the range 0.2-1.2 N.m. The speed commands $\left(N^{*}\right)$ for testing at any load torques are 1000, 1200, 1300, 1400 and $1500 \mathrm{rpm}$. In Table 5, the input powers using the conventional method are compared with the MBM method. In case of $T_{L}=0.2 \mathrm{~N} \cdot \mathrm{m}$ and $N^{*}=1000 \mathrm{rpm}$, the MBM method can save the energy to $48.61 \%$. However, the MBM method cannot save the energy in high load torque cases. From Table 5, the percent of energy saving becomes lower for higher load torque. The MBM drive method can provide the small input power compared with the conventional drive. The small input powers in each situation indicate that the power losses of the motor are small. The power losses for MBM and conventional methods at any load torques and speeds are shown in Fig. 11. From this figure, it can be seen that the region of energy saving is a large area at slight load torque. At high load torque, the region of energy saving becomes small area. The experimental results confirm that the proposed MBM drive method can provide the good result in terms of energy saving for a separately excited DC motor drive system.

\section{Conclusion}

This paper presents the new method to drive the separately excited DC motor called the MBM method. The MBM method provides the good results in case of energy saving compared with the conventional drive method. The parameters of the power loss model are identified by using the adaptive tabu search (ATS) algorithm. This accurate power loss model is used in the MBM method to calculate the field current value for energy saving. The rule based controller is applied to control the field current and speed of the motor to track the command values. The experimental results show that the MBM drive method can provide the minimum losses at any load torques and speed commands. The maximum percent of the energy saving is equal to $48.61 \%$. However, in case of the high load torque values, the MBM drive method cannot provide to save the energy.

\section{Acknowledgements}

This work was supported by Suranaree University of Technology (SUT). 


\section{Nomenclature and Units}

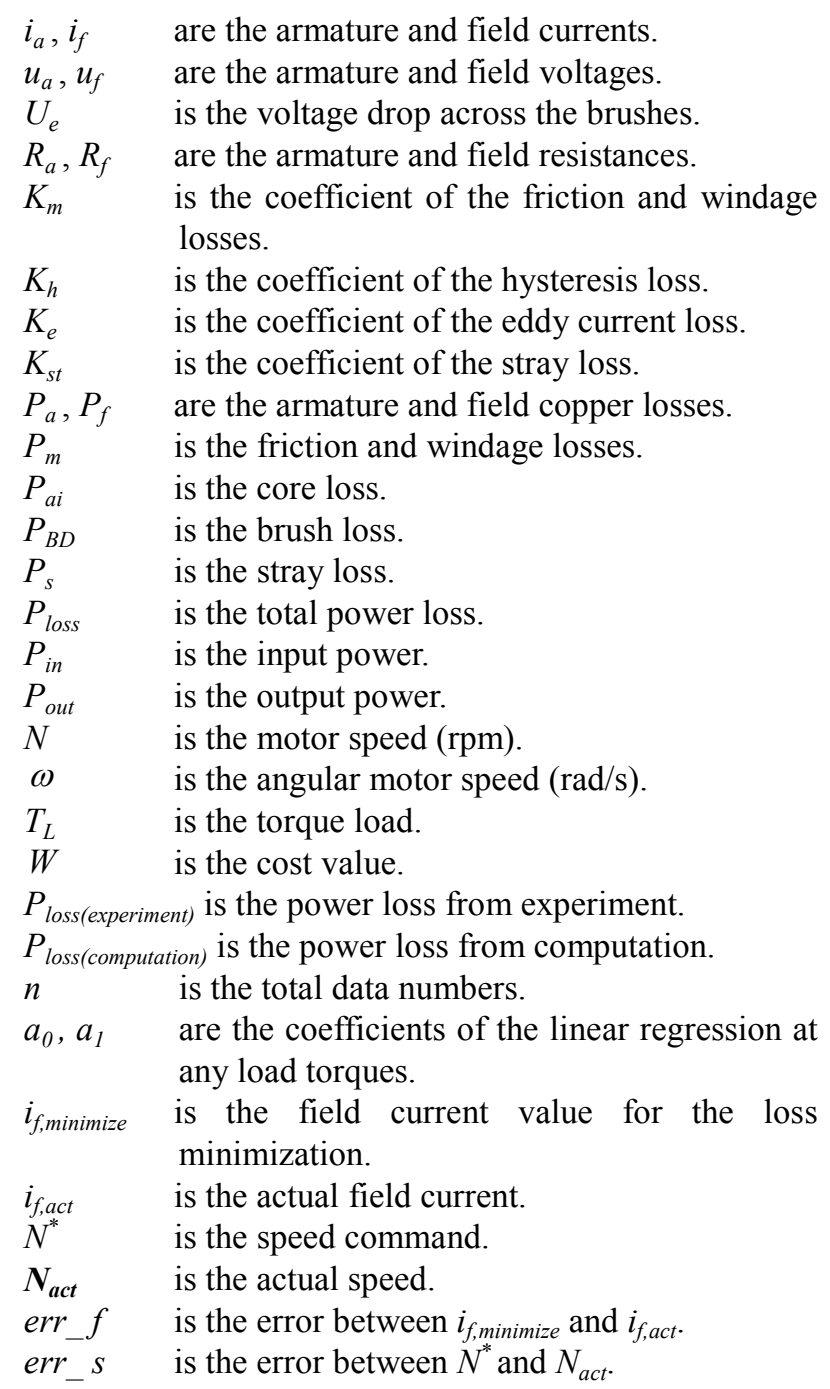

\section{References}

[1] S. J. Chapman, Electric Machinery Fundamentals. 3rd ed., Boston: McGraw, 1999.

[2] A. M. Zaki, A. A. El-Sattar, S. Wahsh, H. M. Mashaly, and S. I. Amer, "Efficiency-Optimized Speed Control for a Separately-Excited DC Motor Using Adaptive Neuroncontroller," IEEE International Conference on Power Electronic Drives and Energy Systems for Industrial Growth., pp. 421-426, 1998.

[3] A. Kusko, and D. Galler, "Control means for minimization of losses in ac and dc motor drives," IEEE Trans. Industrial Application., vol. IA-19, pp. 561570, 1983.

[4] C. D. Angelo, G. Bossio, and G. Garcia, "Loss minimization in dc motor drives," International Conference Electric Machines and Drives (IEMD'99), pp. 701-703, May 1999.

[5] F. F. Bernal, A. G. Cerrada, and R. Faure, "Model- based loss minimization for $\mathrm{dc}$ and ac vectorcontrolled motors including core saturation," IEEE Trans. Industrial Application., vol. 36, no. 3, pp. 755763, 2000.

[6] R. H. Issa, "Separately excited dc motor optimal efficiency controller," International Journal of Engineering and Innovative Technology (IJEIT).vol. 3, pp. 533-539, July 2013.

[7] M. A. Sheta, V. Agarwal, and P. S. V. Nataraj, "A new energy optimal control scheme for a separately excited dc motor based incremental motion drive," International Journal of Automation and Computing., vol. 6(3), pp. 267-276, Aug. 2009.

[8] D. Puangdownreong, K-N. Areerak, A. Sri-kaew, S. Sujijorn, and P. Totarong, "System Identification via Adaptive Tabu Search," IEEE International Conference on Industrial Technology (ICIT'02)., pp. 915920, 2002.

[9] J. Kluabwang, D. Puangdownreong, and S. Sujitjorn, "Multipath adaptive tabu search for a vehicle control problem," Journal of Applied Mathematics., vol. 2012, Article ID 731623, 20 pages, 2012.

[10] D. Puangdownreong, T. Kulworawanichpong, and S. Sujitjorn, "Finite convergence and performance evaluation of adaptive tabu search," in KnowledgeBased Intelligent Information and Engineering Systems, vol. 3215 of Lecture Notes in Computer Science, M. G. Negoita, R. J. Howlett, and L. C. Jain, Ed. Heidelberg: Springer, pp. 710-717, 2004.

[11] T. Kulworawanichpong, D. Puangdownreong, and S. Sujitjorn, "Finite convergence of adaptive tabu search," ASEAN Journal on Science and Technology for Development., vol. 21, no. 2-3, pp. 103-115, 2004.

[12] D. Puangdownreong, S. Sujitjorn, and T. Kulworawanichpong, "Convergence analysis of adaptive tabu search," Science Asia Journal of the Science Society of Thailand., vol. 30, no. 2, pp. 183-190, 2004.

[13] S. Sujitjorn, J. Kluabwang, D. Puangdown-reong, and N. Sarasiri, "Adaptive tabu search and management agent," The ECTI Trans. on Electrical Engineering, Electronics, and Communications., vol. 7, no. 2, pp. 1-10, 2009.

[14] S. Sujitjorn, T. Kulworawanichpong, D. Puangdownreong, and K-N. Areerak, "Adaptive Tabu Search and Applications in Engineering Design," in Integrated Intelligent Systems for Engineering Design, X. F. Zha, and R. J. Howlett, Ed. The Netherlands: IOS Press, pp. 233-257, 2006.

[15] S. Sujitjorn, "Concepts of Design and Implementation of a Real-Time Expert Controller," The 1991 engineering technology symposium and exhibition, Bangkok., pp. 693-703, Oct. 31-Nov. 3, 1991.

[16] V. D. Toro, Basic Electric Machines, New Jersy: Prentice Hall, 1990.

[17] S. A. Nasar, Electrical Machines and Power Systems, New York: McGraw-Hill, 1995. 


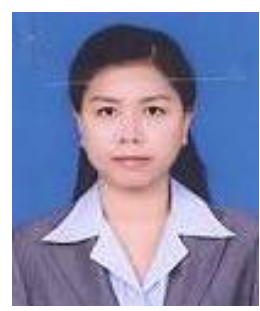

Sasiya Udomsuk was born in Nakhon Ratchasima, Thailand, in 1987. She received the B.Eng and M.Eng degrees in electrical engineering from Suranaree University of Technology (SUT), Nakhon Ratchasima, Thailand, in 2008 and 2011, respectively where she is currently studying toward the Ph.D. degree in electrical engineering. Her main research interests include motor drive, power electronics, AI application and control system.

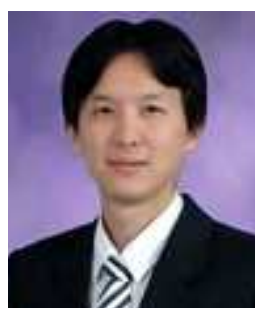

Kongpol Areerak received the B.Eng, M.Eng, and Ph.D. degrees in electrical engineering from Suranaree University of Technology (SUT), Thailand, in 2000, 2003, and 2007, respectively. Since 2007, he has been a lecturer and Head of Power Quality Research Unit (PQRU) in the School of Electrical Engineering, SUT. He received the Assistant Professor in Electrical Engineering in 2009. His main research interests include active power filter, harmonic elimination, artificial intelligence applications, motor drive, and intelligence control systems.

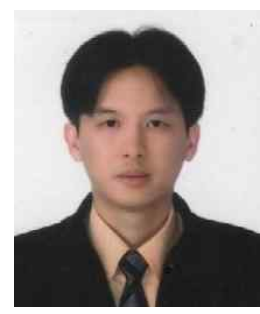

Kongpan Areerak received the B.Eng. M.Eng degrees from Suranaree University of Technology (SUT), Thailand, in 2000 and 2001, respectively and the $\mathrm{Ph} . \mathrm{D}$. degree from the University of Nottingham, Nottingham, UK., in 2009, all in electrical engineering. In 2002, he was a lecturer in the Electrical and Electronic Department, Rangsit University, Thailand. Since 2003, he has been a Lecturer in the School of Electrical Engineering, SUT. His main research interests include system identifications, artificial intelligence applications, stability analysis of power systems with constant power loads, modeling and control of power electronic based systems, and control theory. 